\title{
Compression Therapy for Neuropathy Prevention
}

National Cancer Institute

\section{Source}

National Cancer Institute. Compression Therapy for Neuropathy Prevention. NCI

Thesaurus. Code C157736.

The use of compression garments to prevent the development of peripheral neuropathy. 